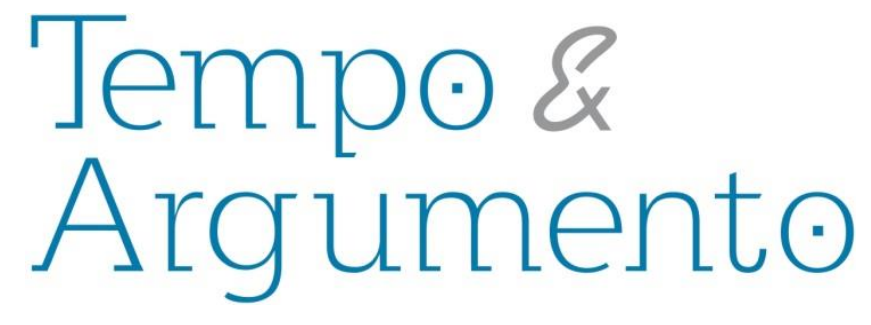

\title{
Colonialismo português e resistências angolanas nas memórias de Adriano João Sebastião (1923-1960)
}

\begin{abstract}
Resumo
Este artigo faz uma discussão sobre a maior presença do colonialismo português no interior angolano na primeira metade do século $X X$ e as resistências a ele. Para tanto, acompanharemos parte da vida do politico Adriano João Sebastião desde o seu nascimento, em 1923, até sua prisão, em 1960, através da análise de seu livro de memórias "Dos Campos de Algodão aos dias de hoje", editado em 1993. Pretende-se, desta forma, entender como o colonialismo português afetou o cotidiano de um homem angolano.
\end{abstract}

Palavras-chave: Angola, Colonização, Resistências; Adriano Sebastião; Memórias.

\section{Washington Santos Nascimento}

Doutor em História Social pela Universidade de São Paulo. Professor da Universidade do Estado do Rio de Janeiro. Brasil washingtonprof@gmail.com

\section{Para citar este artigo:}

NASCIMENTO, Washington Santos. Colonialismo português e resistências angolanas nas memórias de Adriano João Sebastião (1923-1960). Revista Tempo e Argumento, Florianópolis, v. 8, n. 19, p. 283 - 306. set./dez. 2016.

\section{DOI: $10.5965 / 2175180308192016283$}

http://dx.doi.org/10.5965/2175180308192016283 


\title{
Portuguese colonialism in Angola and resistance in Adriano João Sebastião memories (1923-1960)
}

\begin{abstract}
This article aims to make a discussion of the greater presence of Portuguese colonialism in Angola field in the first half of the twentieth century in Angola and the resistance to this colonialism. Therefore we will follow part of the life of the Angolan political Adriano João Sebastião, from his birth in 1923 until his arrest in 1960 , through the analysis of your memory book "From Cotton Fields to today" edited by him in 1993. The aim If this way understand how the Portuguese colonialism affected the daily life of an Angolan man.
\end{abstract}

Keywords: Colonialism; Resistance; Adriano

Sebastião; Memories.

Este artigo tem por propósito fazer uma discussão sobre o colonialismo português e as diferentes formas de resistência a ele no universo rural angolano na primeira metade do século XX. Para tanto, acompanharemos parte da trajetória de Adriano João Sebastião (ou Kiwima, como era também conhecido), desde o seu nascimento, no Bengo (1923), até a sua atuação e prisão em Uíge em 1960. Sebastião viveu de perto o trabalho forçado nas plantações de algodão e, mais tarde, já na hinterland de Luanda, como funcionário público, presenciou a exploração pesqueira e as primeiras articulações de resistência entre os pescadores da região de Cacuaco. 
No artigo, faremos uso das suas memórias, entendidas como sendo uma "memória coletiva”, dentro de um enquadramento social específico, a resistência anticolonial, servindo assim como um elemento de coesão social e construção de uma narrativa para a nação angolana 1 . Apesar da dimensão coletiva, elas apresentam também uma dimensão individual, em dois sentidos: o primeiro, o desejo de Sebastião em contar sua trajetória a seus familiares e, o segundo, a tentativa de preservar (ou reservar?) o seu lugar na história de Angola através das memórias sobre a resistência ao colonialismo português e da construção de um discurso que o coloca no nascimento do Movimento Popular de Libertação de Angola (MPLA), além de aproximá-lo de um dos mais importantes militantes políticos africanos, Amílcar Cabral.

Mesmo sendo uma memória que pode ser também coletiva, convém ressaltar que Sebastião foi uma exceção em Angola. Em um ambiente com mais de 90\% de analfabetos, ele consegui ter acesso à educação formal, além de ter pertencido ao funcionalismo público colonial.

Antes de nos aprofundarmos na análise de sua trajetória, discutiremos sobre a maior presença do aparato colonial português, sobretudo depois da primeira guerra mundial, em diferentes zonas do interior de Angola, destacando as profundas mudanças sociais e econômicas neste período e o consequente acirramento das tensões que levaram ao início da guerra anticolonial em 1961.

\section{Colonialismo português e a ocupação do campo angolano}

A fragilidade europeia ocasionada pelas duas guerras mundiais (1914-1918 e 19391945) e pela grande depressão (1929), fez com que o governante português António Salazar recorresse às potencialidades de suas colônias africanas para assegurar o

\footnotetext{
${ }^{1}$ Segundo Maurice Halbwacs (2004), a memória pode ser entendida enquanto uma reconstrução parcial e seletiva do passado a partir de determinados enquadramentos sociais, como a família, grupos profissionais, classes etc. sendo, por esta razão, coletiva e servindo, assim, como um elemento de coesão do grupo. Outros pesquisadores, a exemplo de James Fentress e Chris Wickham (1994) têm ressaltado também as dimensões individuais do ato de lembrar, ainda que não neguem as influências do contexto social que cercam o indivíduo. HALBWACHS, Maurice. A memória coletiva. São Paulo: Centauro, 2004 e FENTRESS, James e WICKMAN, Chris. Memória social. Lisboa, Portugal: Teorema. 1994.
} 
equilíbrio orçamentário português, promovendo assim uma série de políticas de integração econômica e a ocupação efetiva dos territórios com uma população branca metropolitana. Salazar trocou a política da República (1911-1926), caracterizada pela descentralização administrativa e financeira das colônias, por um modelo mais centralizador e com maior fomento econômico, sobretudo em Angola².

A exportação do café, a mineração de diamantes, o cultivo da cana-de-açúcar, das oleaginosas e do algodão e o comércio de madeira e outros produtos minerais, como o petróleo e o ferro, transformaram Angola em uma das mais rentáveis possessões portuguesas na África, sobretudo pelo uso de força de trabalho compulsória (e barata) local3.

Foi implantada no campo uma série de culturas agrícolas obrigatórias, como o algodão e o café, o que tornou a vida dos nativos angolanos ainda mais difícil, pois foram forçados a abandonar o cultivo de gêneros alimentares o que os deixou em uma situação de vulnerabilidade ainda maior em momentos de seca e intempéries climáticas.

Esses espaços foram integrados por uma extensa via férrea e rodoviária, que objetivava permitir que as mercadorias chegassem ao mercado internacional, por meio da construção de vias que avançavam pelo interior longitudinalmente e, assim, ligavam os pontos extremos da colônia ao litoral ${ }^{4}$. A expansão das vias férreas e da rede rodoviária estimulou a produção camponesa das regiões e de seu entorno e o surgimento de um mercado de trabalho, pois para sua construção foi preciso arregimentar trabalhadores com algum grau de especialização, contratados junto à população nativa.

Estradas de ferro e as novas vias terrestres levavam do interior para o litoral as matérias-primas que abasteceriam o mercado internacional. Os caminhos africanos (ou

2 CASTELO, Claudia. Novos Brasis em África: desenvolvimento e colonialismo português tardio. Varia história. 2014, vol. 30, n. 53, pp. 507-532.

3 SANTOS, Daniel dos. Sociedade política e formação social angolana (1975-1985) In: Estudos Afro-Asiáticos. № 32, Dez. 1997, Rio de Janeiro: Editora Universidade Cândido Mendes, 1997.

${ }^{4}$ As estradas eram pouco operacionais para os angolanos, em função do alto valor de um caminhão. Segundo Maria Madeira dos Santos (1998), "O senhor António Palhares, entrevistado em Lisboa em 1985, relatou, a meu pedido, os primeiros tempos, desde 1926, ao volante do seu primeiro caminhão que comprara a crédito, sujeitando-se a um investimento muito arriscado para a época" (SANTOS, 1998, p. 509). SANTOS, Maria Emilia Madeira dos. Nos caminhos de África. Serventia e Posse. Angola Século XIX. Lisboa, 1998. 
"gentílicos" eram fundamentais, pois estabeleciam ligações no sentido vertical (nortesul) e segundo ela "[...] asseguravam a manutenção de relações seculares ou permitiam às antigas etnias africanas conservarem alguma coesão através dos dois lados de uma fronteira assinalada por marcos de cimento" (SANTOS, 1998, p. 508). Tais rotas formavam uma grande rede que se estendia em múltiplos sentidos a partir de uma organização que obedecia às lógicas próprias angolanas, só compreensíveis para os nativos e alguns poucos iniciados, o que punha em risco os interesses geopolíticos de Portugal de construir em Angola uma malha viária que evidenciasse os espaços já controlados ou ainda a serem controlados 5 .

Esta malha viária cortava os territórios das populações nativas levando a “civilização" portuguesa e desestruturando as organizações políticas, sociais e econômicas locais. As alterações maiores se deram entre os Bacongos-Quikongos, mbundu-Quimbundu e Ovimbundu-Umbundu, que estavam situados nas zonas centrais e no norte de Angola, lugares de maior penetração e ocupação portuguesa.

Assim, em meados do século XX, Portugal já tinha completado um ciclo que redefiniu um novo cenário econômico e social para Angola, caracterizado pela produção extensiva em grandes plantações e pela desestruturação das sociedades africanas tanto no espaço rural quanto no urbano 6 . De que maneira estas populações sentiram estes impactos e de que forma estes alteraram o cotidiano da vida dos angolanos é o que passaremos a ver através das memórias de Adriano Sebastião, Kiwima.

\footnotetext{
${ }^{5}$ CASTRO, Isabel Henriques. Território e Identidade. O desmantelamento da terra africana e a construção da Angola colonial (c. 1872 - c. 1926). Sumário pormenorizado da lição de síntese apresentada a provas para obtenção do título de Professor Agregado do $4^{\circ}$ Grupo (História) da Faculdade de Letras da Universidade de Lisboa. Lisboa. 2003, p. 13.

${ }^{6}$ Como salienta Castelo (2014) "A chegada de colonos brancos, ainda que em números reduzidos, implicou o afastamento da pequena burguesia africana do funcionalismo público e dos empregos mais atrativos e a criação de obstáculos à promoção social dos africanos" (CASTELO, 2013, p. 512). CASTELO, Claudia. Novos Brasis em África: desenvolvimento e colonialismo português tardio. Varia história. 2014, vol. 30, n. 53, pp. 507-532.
} 


\section{Adriano João Sebastião, Kiwima (1923-2010): apontamentos biográficos}

Filho de João Sebastião Kiwima e de Isabel Jerónimo, Adriano João Sebastião, ou Sebastião Kiwima (referência a seu pai), nasceu em Calomboloca, área da comuna de Cassoneca, província do Bengo, aos 11 de agosto de 1923, região de grande produção de algodão e de forte presença portuguesa, tendo migrado em 22 de Abril de 1938 para Luanda, para completar seus estudos.

Depois de fazer o $2 .^{\circ}$ Grau ( $4 .^{a}$ classe) em 1939, foi convidado pela Diretora da Escola da Missão, D. Elisa Klebsattel, para ensinar como professor auxiliar durante aquele ano. Ao longo dos anos, foi professor e funcionário público. Casou-se em 1951 com Hermengarda Paulo de Almeida Sebastião, com quem teve quatro filhas, Isabel Dulce de Almeida Sebastião (a Tinha), Luzia Bebiana de Almeida Sebastião (Gy), Ana Paula de Almeida Sebastião e Adriana Stella de Almeida Sebastião (Didi).

Foi um dos fundadores do Partido de Luta Unida por Angola (PLUA) em 1956, e em 1960 passou a integrar os quadros do Movimento Popular de Libertação de Angola (MPLA), fazendo parte de sua primeira comissão diretiva em Luanda. Preso no ano de 1960, ficou detido de 1961 a 1967.

Com a independência de Angola, em 1974, passou a ocupar cargos administrativos e políticos no novo governo independente, sendo por alguns anos embaixador de Angola em Portugal (1978 a 1982). Publicou dois livros de memórias, "Dos Campos de Algodão aos dias de Hoje” (1993) e “ Missombo" (2012). Adriano João Sebastião faleceu no ano de 2010, em Luanda, aos 87 anos.

O livro de memórias "Dos campos de algodão aos dias de hoje” é dividido em treze capítulos que vão desde a vida no interior angolano, a migração para Luanda até a ascensão dentro do estado angolano pós-independência. Em grande parte, retrata diferentes dimensões da resistência anticolonial nos anos quarenta e cinquenta, na região rural de Calomboloca, Cassoneca e Catete e de forma geral na província de Icolo e Bengo.

Nesta obra há uma preocupação de Sebastião em detalhar genealogias e nomes por ele considerados importantes para sua história. Amadou Hampâté Bâ (2012), apesar de se referir às tradições da região de savana ao sul do Saara (sobretudo Mali), nos ajuda 
a entender Sebastião (1993) como um genealogista, qualidade que expressa, sobretudo, no primeiro capítulo “Kalomboloca 1932-38” em que constrói as genealogias das famílias mais antigas de sua região de origem. Hampâté Bâ (2012) diz que a genealogia é um sentimento de identidade e forma de exaltar a glória da família. Sebastião (1993) também pode ser entendido na acepção de Jacques Le Goff (2004) como “homem-memória”, ou seja, indivíduos de sociedades predominantemente orais que são os "genealogistas" e tradicionalistas daquela sociedade. São a "memória da sociedade", depositários, ao mesmo tempo, da história "objetiva" e da história "ideológica"7.

"Dos Campos de Algodão..." fora construído para suas filhas, para "dizer" e "contar", "[...] donde viemos, o que ouvimos e fizemos até o momento que escrevemos" (SEBASTIÃO, 1993, p. 132). Nesse sentido, as memórias de Sebastião, além do discurso para si e para os outros (a memória coletiva), apresenta também uma dimensão intermediária, os próximos. Segundo Paul Ricoeur (2007), os “[...] próximos, essas pessoas que contam para nós e para as quais contamos, estão situadas numa faixa de variação das distâncias na relação entre o si e outro" (RICOEUR, 2007, p. 141). Assim, a narrativa de Sebastião é também um discurso para suas gerações posteriores.

O livro começa com uma referência aos ancestrais citando 80 nomes de "mais velhos" da região. Diz ainda ser esta a região onde vivera o escritor Uanhenga Xitu, de quem era primo. Faz também questão de salientar que um dos personagens mais emblemáticos da literatura angolana, o Mestre Tamoda, personagem criado por Xitu, de fato existira e vivera na região:

Ele era Kamoda e não Tamoda. O seu nome completo era: Jorge António Kamoda, era natural de Kionzo. Veio para Kalomboloca com seu irmão António Soares ou trazidos por sua tia Luiza Antônio (Kangulu Kathoni) depois da morte da mãe e porque Luiza Antonio tinha amigado na família dos Fortunato. Eram miúdos e cresceram em Kalomboloca. (SEBASTIÃO, 1993, p. 18)

7 BÂ, Amadou Hampâté. A Tradição Viva. In. KI-ZERBO, Joseph. (Org.). História Geral da África I: metodologia e pré-história da África. 2. ed. rev. Brasília: UNESCO, 2010 e LE GOFF, Jacques. Memória In: LE GOFF, Jacques. História e Memória. 5. ed. Campinas: Editora da UNICAMP, 2003. 
Kamoda teria se tornado um lavrador, mas "muito limpo, tão limpo e asseado" que depois de um dia de trabalho na enxada vestia-se todo de branco, calção de brim, camisa de meia manga, sapatos brancos, meias altas e capacete. O nome Tamoda seria uma variação de Kamoda, apelido jocoso que significa em quimbundo, homem da moda. Ele andava com um dicionário de português nas mãos explicando a quem perguntasse algumas palavras em português, sendo por isso tratado de maneira discriminativa ${ }^{8}$.

O relato da história de Kamota/Tamoda logo após a descrição dos "mais velhos" serve por um lado por mostrar a importância da região, diante de um personagem tão significativo da literatura angolana e por outro critica a associação dos nativos aos modelos impostos pelo colonizador. Depois disso Sebastião passa a discutir sobre as plantações de algodão entre os anos de 1932-1938, em Calomboloca, na província do Bengo.

\section{Os campos de algodão de Calomboloca}

A região é descrita por Sebastião (1993) como grande produtora de algodão com uma forte presença portuguesa e missionária. Segundo ele, sua infância na década de 1930 foi um período de muita violência, por conta da pobreza de seus pais, sendo incomodado pelos quimbares e representantes da autoridade administrativa portuguesa no local, bem como pelos sobas das aldeias, sendo obrigado a fazer o primeiro trabalho forçado no conserto da estrada que ligava Luanda a Malanje?.

\footnotetext{
8 No conto de Xitu Tamoda, a personagem, subverte a linguagem colonial, criando traduções e interpretações muito próprias da língua portuguesa. XITU, Uanhenga. "Mestre" Tamoda \& Kahitu: contos. São Paulo: Ática, 1984.

9 Os Kimbares foram africanos retornados do Brasil, escravos que acompanhavam os seus patrões portugueses saídos de Pernambuco em face das hostilidades nativistas, em maio de 1849. Essa designação passou a valer para outros grupos sociais "nativos" que se associavam aos portugueses. Já os sobas eram autoridades tradicionais angolanas que naquele contexto auxiliavam a administração colonial, visto que aqueles que se contrapusessem eram afastados pelos colonizadores. OLIVEIRA, Mario Antonio Fernandes. Reler África. Instituto de Antropologia. Universidade de Coimbra, 1990.
} 
Imagem 1 - Calomboloca (demarcado com símbolo em azul)

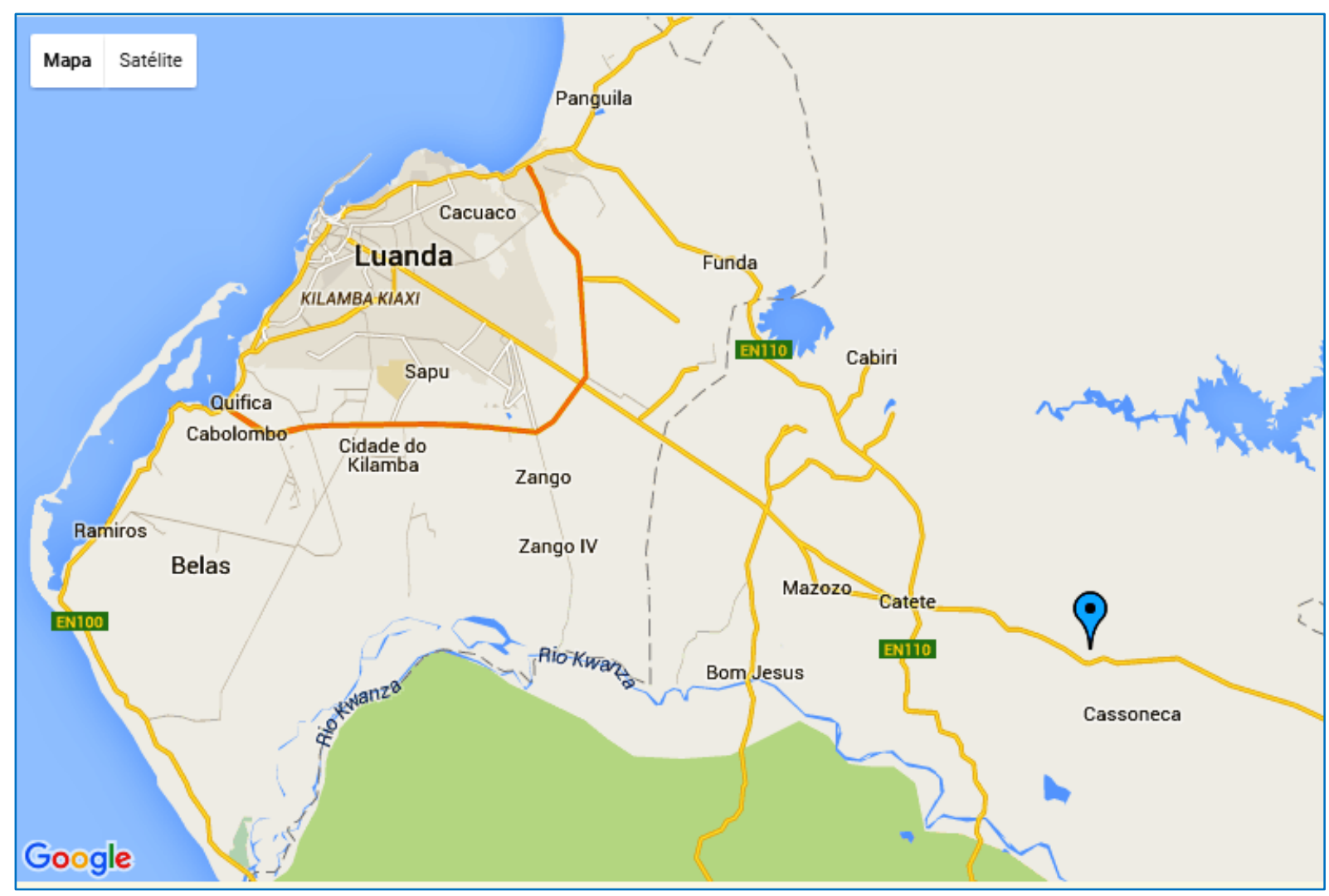

Fonte: http://www.maplandia.com/angola/bengo/icolo-e-bengo/calomboloca/

Segundo o Estatuto do Indigenato (1926 -1961), um conjunto de leis portuguesas criadas para "organizar" e "controlar" as suas colônias, o trabalho forçado era estipulado para todos os africanos do sexo masculino, entre dezenove (19) e cinquenta e cinco anos (55), que não tivessem nenhum tipo de deficiência e que trabalhassem empregando seus serviços a outros ${ }^{10}$. Assim como eles não tinham como pagar os impostos com produtos próprios, as autoridades administrativas legalmente os recrutavam, durante seis meses, para o trabalho obrigatório ${ }^{11}$. No relato de Sebastião (1993), é possível perceber que a

10 Uma discussão sobre este estatuto é feita por Nascimento (2013) e Elizabeth Cruz (2005). NASCIMENTO, Washington Santos. Gentes do Mato: os "novos assimilados" em Luanda. Tese de Doutorado em História Social. Faculdade de Filosofia Letras e Ciências Humanas da Universidade de São Paulo, São Paulo, 2013. CRUZ, Elizabeth Ceita Vera. O Estatuto do Indigenato e a legalização da discriminação na colonização portuguesa: o caso de Angola. Lisboa. Novo Imbondeiro. 2005.

11 CASTELO, Cláudia. Passagens para África. O Povoamento de Angola e Moçambique com Naturais da Metrópole, Porto, Edições Afrontamento, 2007, p. 313. 
idade mínima do recrutamento era ilusória, pois com dez (10) anos ele foi levado para o trabalho obrigatório:

É que a pobreza de meu pai era tal, em termos monetários que não tinha dinheiro para dar aos Kimbares quando esses aparecessem para nomear para o serviço de estrada de forma que ainda fiz duas campanhas desses serviços de três semanas cada uma e a máxima e última aconteceu em 1933, já eu tinha 10 anos, quando apareceu à calada da noite, o Kimbar António Afonso, para me arrancar da cama de minha mãe, a fim de ir em Cabiri, como contratado do Campo de Algodão de Carlos Jorge, o kipuka, para a campanha de algodão durante seis meses. Meu pai nada pôde fazer e minha mãe muito menos e fui. (SEBASTIÃO, 1993, p. 25)

Cabiri, região a que se refere Sebastião (1993), é uma povoação rural que fica no município do Icolo e Bengo ${ }^{12}$. Em meados do século XX, ficou conhecida por sua grande produção de algodão e pela instalação, em 1962, de um colonato de imigrantes das ilhas cabo-verdianas de Morabeza'13.

Em relação ao trabalho forçado em Angola, fazendo uso de indicadores coloniais, Solival Menezes (2000) afirma que entre os anos de 1935 e 1939 o governo metropolitano utilizava 720 mil pessoas por $a^{14}$. Segundo ele, a maioria desses contratados estava concentrada em duas regiões produtora de café, Cuanza Norte e Uíge, embora estes

${ }^{12} \mathrm{O}$ município de Ícolo e Bengo está subdividido em cinco comunas: Bom Jesus, Cabiri, Cassoneca, Caculo Cahango e Catete. Do Cabiri vieram Xitu e Sebastião, de Cassoneca Jacques Arlindo dos Santos e do Catete Agostinho Neto.

13 Atualmente, nesta região, praticamente não se produz mais algodão, sendo tal cultura suplantada pela criação de gado. Autoridade Mabuia afirma ser possível retorno produção algodão. Agencia Angolapress, 04 de julho de 2005. Disponível em http://www.portalangop.co.ao/motix/pt_pt/noticias/economia/ Autoridade-Mabuia-afirma-ser-possivel-retorno-producao-algodao,c784f273-e7b1-4ba7-aab7a8888fofdog5.html. Acesso em 11 de agosto de 2012.

14 O Código do Trabalho do Indígena nas Colônias Portuguesas de África Portuguesa, aprovado pelo Decreto 16199, de 6 de Dezembro de 1928, distinguia na colônia quatro formas de prestação de serviços por parte daqueles considerados indígenas: primeiro, o trabalho voluntário que, apesar do nome, o "indígena" era obrigado a aceitar o patrão e o salário mínimo que as autoridades designavam; Trabalho compulsório ou "contrato", o recrutamento era feito através do recurso aos sobas ou de indivíduos encarregados pelos patrões de fazê-lo, os chamados angariadores; contrato feito por parte do Estado. Este recrutava tanto para si como para os colonos e, por fim, o trabalho por conta própria, através da imposição aos agricultores indígenas de culturas obrigatórias. Código do trabalho dos indígenas nas colónias portuguesas de Africa; decreto n.o 16:199, de 6 de dezembro de 1928. Suplemento ao B.O.M.n 2, la. Série, de 16.01.1929 pp. 19-62 
fossem imigrantes de Huambo e Bié, região predominantemente ovimbundo ${ }^{15}$. Sobre o cotidiano nos campos de algodão, diz Sebastião (1993):

Na Kipuka para ser livre das palmatórias com que eram brindados os contratados, cada um tinha de encher três sacos de algodão que eram calcados para pesarem entre 80 a 100 kgs. Pequeno como era não conseguia encher os três sacos de modo que as três primeiras semanas foram de apanhar palmatória dia sim dia não até que o mais velho Deão, meu companheiro da sanzala e outros que eu não conhecia resolveram ajudar-me enchendo dois dos meus sacos porque eu só conseguia um. (SEBASTIÃO, 1993, p. 25)

O uso dos castigos no trabalho forçado era comum no império português e eram justificados pelas autoridades metropolitanas que afirmavam que o "indígena" não sentiria tanto o receio da prisão, mas sim da punição corporal imediata ${ }^{16}$. Associado ao excesso de castigos corporais, grandes jornadas de trabalho, más condições de moradia e alimentação faziam com que, não raro, esses trabalhadores construíssem relações de solidariedade e estratégias para fugir ${ }^{17}$.

Segundo Claudia Castelo (2007), a própria direção dos serviços dos negócios indígenas reconhecia que em muitos casos os castigos corporais por faltas insignificantes eram recorrentes, chamando atenção de que era necessário torná-los mais "paternais", [...] como, aliás, se usou durante muito tempo nas escolas, e até na família, desde que aplicado moderada, consciente e humanamente (CASTELO, 2007, p. 287).

Além dos castigos corporais, outra forma instituída pela administração colonial de espalhar o medo pelas zonas suburbanas das cidades ou pelas povoações rurais foi a prática das chamadas "rusgas", uma espécie de diligência policial, para prender pessoas consideradas "desordeiras", frequentadoras de lugares ditos suspeitos e, sobretudo,

\footnotetext{
${ }^{15}$ Para fazer esta afirmação, Solival Menezes (2000) faz uso dos boletins coloniais produzidos em Angola na segunda metade do século XX. MENEZES, Solival. Mamma Angola: Sociedade e Economia de um país nascente. Prefácio de Paul Singer. São Paulo: Edusp; FAPESP, 2000, p. 139.

${ }^{16}$ CASTELO, Cláudia. Passagens para África. O Povoamento de Angola e Moçambique com Naturais da Metrópole, Porto, Edições Afrontamento, 2007, p. 298.

${ }^{17}$ Idem.
} 
aquelas que não portassem documentos obrigatórios (a caderneta indígena) ou fossem considerados vadios, fugidos ao contrato etc. ${ }^{18}$

A grande quantidade de fugas preocupava as autoridades portuguesas, bem como a intelectualidade lusa. Afonso Mendes (1958), ao se referir a esta situação em seu trabalho de pesquisa sobre Huíla e Moçamedes, comenta que "O abandono do emprego pelos trabalhadores indígenas assume uma transcendência notória no conjunto econômico angolano" (MENDES, 1958, p. 72). Ele destaca que em muitas vezes os "contratos" eram rompidos por mais de $90 \%$ dos trabalhadores que simplesmente fugiam dos campos de trabalho. Como também fez Sebastião (1993):

Depois de um mês e duas semanas o mais velho Deão achou que aquela situação era de tal maneira insuportável que não podia aguentar-se mais e resolveu que devíamos fugir. E se bem o pensou melhor seria o pormos em prática antes que fossemos descobertos porque em locais de martírios como esse nunca faltam aqueles que colaboram com os guardas [...] Na madrugada de um dia que não me lembro se segunda ou terça, mas me parece segunda pelo tempo que andamos, só de noite, porque de dia tínhamos de nos esconder no capim para não sermos apanhados antes da formatura da manhã para conferência do pessoal, mais velho Deão e eu fugimos do Kipuka em direção a Mbanza Kitele indo refugiarmo-nos na casa de Adão Bernardo. (SEBASTIÃO, 1993, p. 26)

Diante da situação classificada como “insuportável” e mesmo podendo ser denunciado por outros africanos, ele conseguiu fugir, mas além de colocar sua vida em risco, expôs sua mãe que, sem saber que seu filho tinha fugido, foi até o campo de algodão para visitá-lo. Dando conta da situação, a mãe de Sebastião também resolveu evadir-se:

[...] e segundo nos contou minha mãe depois de sentir frio na barriga, isto é as carnes da pele da barriga doída do tanto que se arrastou resolveu parar e meter-se num buraco que lhe apareceu para descansar e porque estava escuro já, decidiu nesse buraco dormir e ainda ouviu, porque o vento soprou na direção em que se encontrava, os guardas dizer: Se lhes apanhássemos ..., teve sorte filho da puta da mãe dele... os nossos cães the rasgariam a pele e lhe comeriam - a. (SEBASTIÃO, 1993, p. 26)

\footnotetext{
18 Novamente vale a pena destacar o trabalho de Claudia Castelo (2007). CASTELO, Cláudia. Passagens para África. O Povoamento de Angola e Moçambique com Naturais da Metrópole, Porto, Edições Afrontamento, 2007, p. 299.
} 
Nesse relato, Sebastião (1993) constrói a imagem do sistema colonial português marcado pela violência que, com a colaboração de guardas africanos, não poupava nem mulheres ou pessoas idosas. Dias mais tarde, encontraram sua mãe e retornaram para Calomboloca, onde refugiaram-se em uma plantação. Depois de cerca de um mês, foram descobertos pelo "kimbar" (nome dado ao guarda angolano) que não se importou muito, diferente do soba local, Kaioho de Nganga zuze (de nome português Manuel da Costa Fernandes) $)^{19}$.

Elisabete Silva (2003) diz que esses sobas não foram incorporados na sistemática formal da administração colonial, mas eram instrumentos indispensáveis para o sucesso da colonização portuguesa em Angola; entretanto, não era qualquer um que se tornava soba naquele cenário de colonização portuguesa, pois Portugal depôs autoridades locais tradicionais mais rebeldes e colocou em seus lugares chefes mais colaborativos, que agiam em parceria com os "séculos de posto", chefes das unidades políticas agropastoris em que a instituição dos chefes hereditários não existia ${ }^{20}$. Com receio de alguma atitude do soba local, e para evitar que alguma coisa ruim pudesse acontecer com Sebastião, sua mãe o enviou para a escola da missão protestante de Icolo e Bengo, administrada pelo pastor Cristóvão Agostinho de Carvalho.

Na história construída em seu depoimento, alguns traços comuns da vida dos angolanos os quais ele procurou denunciar: a exploração colonial associada ao trabalho forçado e à violência física, o compromisso e colaboração que as autoridades locais nativas assumiam, muitas vezes, com o colonizador; a fuga enquanto um ato de resistência e, por fim, a educação dentro das missões protestantes ${ }^{21}$.

O fato de ter tido acesso àq escola colonial possibilitou a Sebastião transferir-se para Luanda anos mais tarde (em 1938), depois de haverterminado a segunda classe. Em Luanda, conseguiu continuar seus estudos tornando-se professor na capital para turmas das primeiras e segundas classes (anos), cargo que exerceria de maneira provisória e por

\footnotetext{
19 SEBASTIÃO, Adriano. Dos campos de algodão aos dias de hoje. Edição do Autor, 1993, p. 28.

20 SILVA, Elisete Marques. Impactos da ocupação colonial nas sociedades rurais do Sul de Angola, Lisboa: Centro de Estudos Africanos/ISCTE-Instituto Universitário de Lisboa, 2003.

${ }^{21}$ Washington Nascimento (2014) destaca em outro trabalho: a formação escolar de Sebastião dentro das escolas missionárias, tanto em Calomboloca, quando em Luanda. NASCIMENTO, Washington Santos. Minha mãe me entregou nas mãos do professor para fazer de mim o que quisesse e pudesse?: memórias da educação escolar em Angola. Revista HISTEDBR On-line, v. 55, p. 231-249, 2014.
} 
poucos anos (1940-1947), tendo prestado concurso e sendo admitido como funcionário público um pouco depois (1948).

\section{O comércio de Peixe em Cacuaco e o inicio da atuação política (1948 - 1958)}

Depois de trabalhar como professor na Missão Metodista de Luanda, Sebastião foi aprovado em um concurso público e passou a desempenhar a função de Fiscal Cobrador dos Mercados e apesar de ter sido o primeiro colocado e que por isso teria o direito de trabalhar no Mercado Principal de Luanda, foi enviado para outro, também de Luanda, mas afastado do centro, o mercado de Cacuaco. "O mercado de Cacuaco competia ao candidato que ficasse em $3^{\circ}$ lugar, mas o negro não podia ficar entre os brancos sob pena de os manchar com a sua cor, tinha de estar afastado, por isso o seu lugar era Cacuaco e fomos" (SEBASTIÃO, 1998, p. 54-55). Sebastião ficou em Cacuaco dez anos (1948 - 1958), sendo depois transferido para as Ingombotas em Luanda.

\section{Imagem 2 - Cacuaco (Com leve realce em vermelho)}

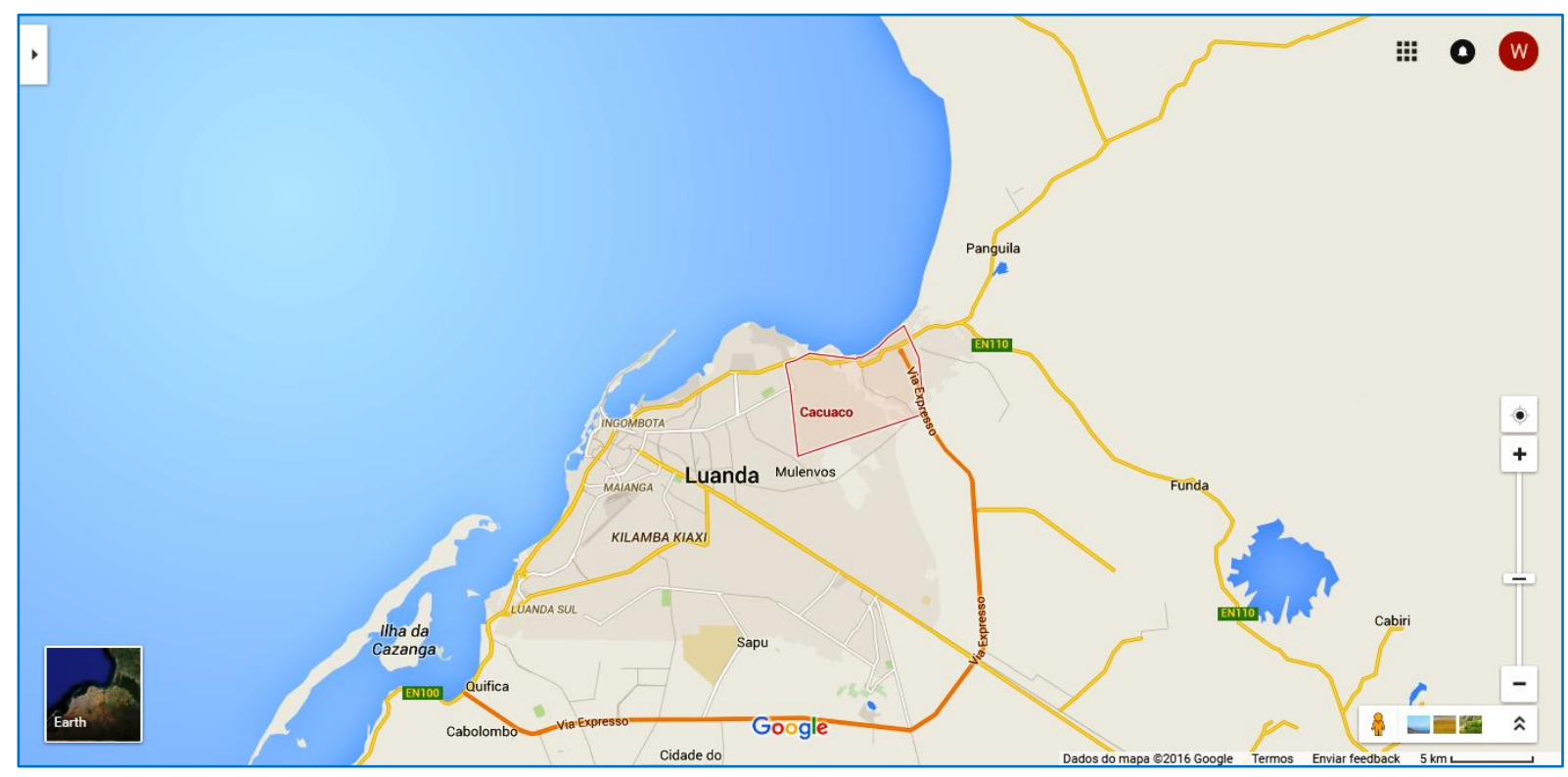

Fonte: https://www.google.com.br/maps/place/Cacuaco,+Angola

Cacuaco foi descrito por Sebastião (1993) como o local mais importante de produção do pescado no mar da costa de Luanda. Segundo ele, de lá saia o melhor camarão da costa, bem como uma diversidade de peixes, retirados em redes de arrasto e 
de armação pelos pescadores nativos locais. Quando chegara no ano de 1948, existia apenas um homem branco na localidade, que se chamava Martins Latagaio e comprava todo o peixe dos pescadores locais, atuando como um atravessador. Com o passar dos anos, este mesmo português mandou fazer suas próprias redes, contratou pescadores e se pôs também a pescar, mas continuando a comprar os peixes dos demais. A partir dos anos de 1950, "outros brancos" começaram a chegar para negociar com os pescadores locais.

Em 1958, uma lei metropolitana proibiu a pesca em alto mar sem a utilização de barcos a motor, mais caros e pertencentes aos portugueses. Esta medida trouxe ainda mais dificuldades para os pescadores nativos. Américo Boavida (1967) diz que o objetivo seria "[...] colocar, da noite para o dia, os africanos na situação de assalariados dos pescadores europeus. Com esse decreto desaparecia o último setor independente da economia tradicional africana!” (BOAVIDA, 1967, p. 49). Apesar do exagero desta afirmação, é fato que o setor pesqueiro nativo entrou em declínio e levou os pescadores a buscarem formas de se associarem para resistir ao colonialismo.

É justamente neste contexto que Sebastião começa a sua atuação política, sobretudo a partir do contato com Manuel Bento, enfermeiro, natural de Cassoneca, Icolo-Bengo, mesma região de Sebastião. Bento foi um dos responsáveis por levar a ele a situação do campo angolano; através de longas conversas na madrugada, relatava a dureza do trabalho de limpeza do cafezal e da colheita do café, as empreitadas em termos de sacos de café, o trabalho exaustivo e o fato de que o contratado não poder ficar doente, apesar de ser acometido pelo escorbuto, uma doença ocasionada pela precariedade da alimentação, além disso:

[...] que muitas vezes os contratados eram levados ao posto administrativo para serem sovados com palmatoadas sem pretexto válido apenas para lhes incutir o respeito e sobretudo o medo ao homem branco que deve ser cegamente obedecido: que contratado ou o preto tinha de encarar o homem branco como todo poderoso, infalível e justo em todo o tratamento dado ao preto porque era apenas um indolente, manhoso, gentio, matumbo que era preciso educar a obedecer e isso só com pancada que não excluía a morte. (SEBASTIÃO, 1993, p.67) 
Ao relato de Bento, Sebastião (1993) registra também o racismo do branco para com o negro e que o "[...] preto pescador dali nunca iria conhecer-se a si mesmo e ao seu valor como elemento da sociedade se não organizasse e se não aprendesse a ler" (SEBASTIÃO, 1993, p. 68). A partir de então, ele, mesmo sendo protestante, começou a articular junto com padres locais para que nesta região se fizesse uma escola.

Neste momento, também toma contato com o Partido da Luta Unida dos Africanos de Angola (PLUAA), passando a formar células clandestinas para divulgar a organização e organizar ações de resistência ao colonialismo português. Na prática, eles deveriam sabotar a atividade pesqueira dos brancos fazendo grandes furos em suas redes de pesca, boicotando desta forma a atividade. Além de incitar os pescadores a se sindicalizarem e a exigirem melhores salários, contando para isso com os auxílios de Domingos António Lopes, Alexandre Agostinho e António Diogo da Silva. Somou-se a este primeiro grupo, Antonio Jacinto do Amaral Martins (A.J.) e Mario Antônio Fernandes de Oliveira (M.A), que chegara à região no ano de $1955^{22}$. Estas ações resultara na fundação da Cooperativa dos Pescadores de Cacuaco, que passou a organizar os trabalhadores locais.

\section{A presença de Amílcar Cabral no campo angolano}

É em Cacuaco que Sebastião conheceu um dos principais militantes anticolonialistas do continente africano, o guineense Amílcar Cabral, quando este chegou à região em 1955. Cabral esteve em Angola entre os anos de 1955 e 1958 trabalhando como engenheiro agrônomo em três fazendas, Cassequel, Tentativa e São Francisco e desenvolvendo uma série de atividades de cartografia e recuperação de solos salgados ${ }^{23}$.

\footnotetext{
${ }^{22}$ Anos mais tarde, em 1963, Mário António Fernandes de Oliveira iria viver em Portugal, onde se tornaria um dos maiores intelectuais angolanos, como uma vasta produção, tanto literária quanto acadêmica. Suas publicações mais importantes foram o livro "Crônica de uma cidade estranha" (1964), além dos ensaios "A Formação da Literatura Angolana, 1851-1950" (1987) e a obra que reúne vários textos seus "Reler África" (1990).

${ }^{23}$ FRANCO, Paulo Fernando Campbell. Amilcar Cabral: a palavra falada e a palavra vivida. Mestrado em História Social. Universidade de São Paulo, São Paulo, 2009, p. 131.
} 
Sua missão pública era o estudo dos solos da região do Dande, sobretudo na fazenda Tentativa, mas, na prática, construía redes clandestinas de resistência ao governo português e por isto já tinha informações sobre Sebastião, provavelmente oriundas de Deolinda Rodrigues de Almeida ou Noé da Silva Saúde, personagens importantes da luta anticolonial, com a qual Sebastião tivera contato em Luanda ${ }^{24}$.

A Fazenda Tentativa, onde Cabral trabalhava, era uma das mais importantes possessões portuguesas além-mar e era "modelar" para a exploração colonial, sobretudo no que no que concernia à forma "científica" como produzia o açúcar, ou mesmo extraia o óleo de palma ${ }^{25}$. Ela era propriedade da Companhia de Açúcar de Angola, a segunda maior produtora de cana-de açúcar da então colônia. Durante o período em que Cabral esteve a serviço desta Companhia (1956 a 1957), só na fazenda Tentativa foram extraídas cerca de 23.589 toneladas de açúcar, 308 toneladas de coco, e 820 de óleo de palma (azeite de dendê), obtendo para tanto um lucro de um milhão de dólares ${ }^{26}$.

Ao voltar da fazenda, nos fins da tarde, Cabral parava em Cacuaco para realizar encontros com os pescadores e militantes políticos locais. Sebastião destaca que as conversas giravam em torno da vida da população do lugar, bem como sobre as ações de escolarização (e politização) feitas junto à juventude e, por fim, sobre a cooperativa dos pescadores, fundada com o auxílio do Antônio Jacinto e Mario Antônio. Ao associar Cabral a sua atuação política em Cacuaco, Sebastião de certa forma buscou uma validação histórica como também um personagem importante e central da luta anticolonial.

24 Deolinda Rodrigues de Almeida nasceu em Catete no ano de 1939. Prima de Agostinho Neto, foi guerrilheira e dirigente do MPLA, sendo a única mulher no Comitê Diretor da organização. Filha de um pastor metodista, estudou no Brasil e também nos Estados Unidos, regressando à África em 1962, para se juntar ao MPLA no Congo Léopoldville. Já Noé Saúde, foi um dos mais jovens dentre os presos pelas autoridades portuguesa, em 1959, por supostos atos contra a metrópole portuguesa. Figurando Noé no primeiro dos três processos que, em seu conjunto, ficou conhecido como "Processo dos cinquenta". PAREDES, Margarida Paredes. Deolinda Rodrigues, da Família Metodista à Família MPLA, o Papel da Cultura na Política. Cadernos de Estudos Africanos [Online], 20, 2010, posto online no dia 22 Julho 2012, consultado em 11 Junho 2016. URL: <http://cea.revues.org/135>; DOI: 10.4000/cea.135. MEDINA, Maria do Carmo. Angola: Processos Políticos da Luta pela Independência. ed. Coimbra: Almedina, 2005.

25 RODRIGUES, Alberto Leite. A indústria química nas colónias: Elementos colhidos no cruzeiro de férias. Disponível em http://www.spq.pt/magazines/RCPA/487/article/10001262/pdf. Acesso em 10 de Junho de 2016.

${ }^{26}$ CASSAMA, Daniel Júlio Lopes Soares. Amílcar Cabral e a independência da Guiné-Bissau e Cabo Verde. Dissertação de mestrado em Ciências Sociais. Faculdade de Ciências e Letras. UNESP, Araraquara, São Paulo, 2014. p. 59. 
Ao retornar para Luanda, no mercado das Ingombotas, Sebastião novamente encontrou ele em Kinaxixe, um dos mais famosos musseques da capital ${ }^{27}$. No Kinaxixe, se reuniam com jovens como os anteriormente referidos Noé Saúde e Deolinda Rodrigues, além de Deolinda Bebiana.

Reuniões a que assistimos e cuja tônica era a organização para a luta que era a única forma de acabar com a dominação e exploração estrangeira no país. Orientada no sentido da constituição de núcleos de jovens decididos nos bairros com missões específicas como destruição clandestina de estruturas econômicas dos brancos e o apego da juventude aos estudos, visto que só formados se poderia discutir de igual para igual, no campo político, com o branco. (SEBASTIÃO, 1993, p. 75)

Neste espaço também se divulgou as intenções do Partido da Luta Unida dos Africanos de Angola (PLUAA), o primeiro grupo do qual Sebastião participou e no qual Cabral também estava, de certa maneira, segundo Sebastião, associado, pois foi ele um dos fundadores em 1956.

Em entrevista dada a Oleg Ignatiev (1984) o também militante político angolano Gabriel Leitão disse que Cabral tinha uma função de grande importância na PLUAA, selecionando entre os jovens os candidatos a serem enviados ilegalmente para a Argélia, onde os mesmos iriam ser preparados como combatentes dos futuros destacamentos armados do MPLA ${ }^{28}$. Já Tomas Medeiros, em depoimento dado a Wilmer Pinto (2014), disse que Cabral era um dos responsáveis por produzir textos e panfletos anticoloniais que eram disseminados nos musseques. Participou também de maneira direta com Mário de Andrade (antigo companheiro de Sebastião em Cacuaco), Agostinho Neto, entre outros, da elaboração do Manifesto que posteriormente daria origem ao MPLA ${ }^{29}$.

Segundo Dalila Mateus e Álvaro Mateus (2011), esta organização nascera como uma frente que agrupava pessoas de várias tendências e grupos políticos e ideológicos, a exemplo do PLUAA, agrupamento este que Sebastião ajudou a fundar. Desta forma, ele

\footnotetext{
${ }^{27}$ Musseque é uma denominação em quimbundo para uma comunidade periférica dentro de Luanda, tendo por isso certa equivalência ao que chamamos no Brasil de favela.

28 OLEG, Ignatiev. Amílcar Cabral. Moscovo: Edições Progresso. 1984, p.101.

29 PINTO, Wilmer Delgado Pinto. Caraterização do comando e liderança de Amílcar Cabral. Relatório Científico Final do Trabalho de Investigação Aplicada. Academia Militar. Lisboa, 2014, p. 18.
} 
foi incorporado ao MPLA, mas não fez parte do corpo diretivo fundador, atuando mais na retaguarda do que na linha de frente, como deixa evidente o evento que levara a sua prisão em $1960^{30}$.

\section{A prisão}

Em 1960, junto com 38 outros angolanos, Adriano Sebastião foi preso, acusado, dentre outras coisas, de ter recebido em sua casa em Uíge, para onde havia sido transferido naquele ano, ainda pelo setor de obras públicas, uma missão do então nascente MPLA que iria para o então Congo Leopoldville (atual República Democrática do Congo) comemorar a sua independência.

Segundo ele, foi neste ano (1960) que o MPLA teria sido criado e que esta primeira missão enviada ao país vizinho fora composta por Bernardo d’Eça de Queirós, Joaquim Bernardo Horácio, Manuel Augusto da Silva Coelho, Domingos Damião Neto, Rodolfo da Ressureição Bernardo, Bernardo Adão e Alberto Fonseca da Conceição ${ }^{31}$. Para se deslocarem por Angola eles se disfarçaram de um grupo musical:

[...] quando a cinco de Junho e só a cinco apareceu a delegação com guitarras, bandolins e o diabo a quatro de instrumentos de música com que andaram se divertindo em vez de pensarem que eram clandestinos e que deviam sair das fronteiras de Angola o mais rápido possível, porque a Pide, através de seus bufos, podia saber dessa viagem e tudo fazer para impedir a sua realização. Na noite em que a delegação chegou praticamente não dormimos. A Hermengada, minha mulher, não teve mãos a medir como se costuma dizer, ao coser os papéis (documentos) que levavam, nos forros para impedir a sua realização. (SEBASTIÃO, 1993, p. 83)

30 Fizeram parte da primeira direção do MPLA, Antônio Agostinho Neto, Joaquim Pinto de Andrade, Bernardo Joaquim Silas, David d'Eça Queirós, Manuel Pedro Pacavira e Fernando Coelho da Cruz. MATEUS, Dalila Cabrita e MATEUS, Álvaro. Angola 61 - Guerra Colonial e consequências. Alfragide. Texto Editores, 2011, p. 64.

${ }^{31}$ Diferentemente da visão oficial de que o MPLA teria sido criado em 1956, Sebastião destaca que ele fora de fato no ano de 1960. Entretanto, esta data dada por ele foi contestada por alguns pesquisadores, a exemplo de Marcelo Bittencourt (1997). BITTENCOURT, Marcelo. A criação do MPLA. Estudos AfroAsiáticos, Rio de Janeiro, v. 32, n. 32, p. 185-208, 1997. 
Três dias depois, no dia 8 de junho, a Polícia Internacional e de Defesa do Estado (PIDE) realizou uma série de prisões em toda a Angola, inclusive dos sete que estiveram na casa de Sebastião dias antes. Sebastião foi preso no dia 15 daquele mesmo mês pelo chefe de Polícia de Uíge. Estes presos políticos de 1960 ficaram conhecidos como "grupo dos 36", apesar de ser composto por 38 pessoas $^{32}$. Eles passaram a cumprir prisão na colônia prisional do Bié e na cadeia do Missombo (Kuando-Kubango).

O grupo era composto em sua maioria por estudantes do ensino secundário do Colégio das Beiras e da Escola Industrial de Luanda, que desde os anos de 1956 a 57 construíram alguma forma de resistência ao colonialismo português, por meio da formação do movimento denominado "Pro-Independência Nacional de Angola", do desenvolvimento de campanhas de alfabetização, educação e mobilização, usando para tanto os poucos textos políticos disponíveis para contestação ao regime português33.

Em um evento realizado em fevereiro de 2006 em Luanda, Adriano Sebastião dissera que este grupo teria dado continuidade ao trabalho iniciado pelos integrantes do chamado "processo dos 50" desenvolvendo um "trabalho intenso" para que a comunidade internacional tomasse ciência do que acontecia em Angola34.

Voltando a 1960, ao ser preso Sebastião foi indagado sobre as razões pelas quais teria se envolvido com aquelas pessoas, ao que respondeu: “ - O povo angolano quer a independência de Angola" (SEBASTIÃO, 1993, p. 85).

\footnotetext{
${ }^{32}$ Além de Sebastião, irão fazer parte do "Processo dos 36", António Agostinho Neto, Joaquim Pinto de Andrade, Adolfo João Pedro, Bernardo Adão Francisco, Bernardo Horácio, Bernardo João Silva, Cândido Fernandes da Costa David Bernardo Queiroz, Fernando Coelho da Cruz, Joaquim Silas e Manuel Pedro Pacavira. MATEUS, Dalila Cabrita e MATEUS, Álvaro. Angola 61 - Guerra Colonial e consequências. Alfragide. Texto Editores, 2011, p. 63.

33 Constituída Associação do Grupo dos 36. Agência Angola Press. Disponível em http://www.angop.ao/angola/pt_pt/noticias/educacao/2007/11/49/Constituida-Associacao-Grupodos,b9460179-276e-4a17-b94d-eebddoobc19d.html. Acesso em 02 de Fevereiro de 2016.

34 SEBASTIÃO, Adriano João. Mérito do processo 50 foi a consciencialização do povo angolano. Agência Angola Press. Disponível em: http://www.angop.ao/angola/pt_pt/noticias/politica/2006/1/7/Meritoprocesso-foi-consciencializacao-povo-angolano,c361f1ae-fb29-4dco-a27f-cfba1ad66261.html. Acesso em 02 de fevereiro de 2016.
} 


\section{Considerações Finais}

Adriano Sebastião faleceu no ano de 2010 em Luanda, aos 87 anos de idade. Foi lembrado como um "homem do MPLA" e "nacionalista", bem como pelo fato de que nos últimos anos de sua vida fora pouco crítico aos "desmandos" do atual presidente Eduardo dos Santos, no governo há mais de trinta anos 35 . A despeito destas considerações, Sebastião foi um homem de seu tempo, suas memórias apesar de estarem atreladas a uma "história oficial" a ser contada pelo MPLA, podem ser entendidas também como uma memória coletiva compartilhada por muitos angolanos que viveram na primeira metade do século XX.

Sua história é importante para percebermos como a opressão do colonialismo chegou à dimensão cotidiana dos angolanos, sobretudo quando ele relatou as perseguições sofridas e o trabalho compulsório ainda em sua infância. O acesso à escolaridade o tornou um funcionário publico e, neste sentido, se percebe em sua trajetória a importância da camada média nativa angola no processo de resistência ao colonialismo português.

Estas resistências devem ser entendidas como um processo múltiplo e plural que incorporava desde o enfrentamento direto (organização de sindicatos, movimentos políticos etc.) até formas mais veladas de subverter a ordem colonial estabelecida (como furar as redes de pesca dos atravessadores portugueses, se fantasiar de músicos para atravessar o país etc. ), usando para tanto as associações locais (sobretudo as redes religiosas protestantes, mas também católicas) como as redes mais amplas e supranacionais (a exemplo do contato com Amílcar Cabral e com os insurgentes do antigo Congo Leopoldville).

Por fim, cabe salientar que "Dos Campos de Algodão aos Dias de Hoje" foi tambémum discurso para as filhas de Sebastião, para que elas reconhecessem a sua genealogia, as histórias e dificuldades pelas quais seu pai passou durante a vida. Nas palavras do próprio Sebastião "Naquilo que eu chamo de dedicatória eu disse que essas

\footnotetext{
35 Adriano Sebastião morre aos 87 anos. Disponível em http://www.angonoticias.com/Artigos/item/25322. Acesso em 10 de junho de 2016.
} 
memórias eram essencialmente para minhas filhas para que elas soubessem um pouco e só um pouco da vida atribulada de seu pai” (SEBASTIÃO, 1993, p. 137).

\section{Referências}

BOAVIDA, Américo. Angola: cinco séculos de exploração portuguesa. Civilização Brasileira. 1967.

BITTENCOURT, Marcelo. A criação do MPLA. Estudos Afro-Asiáticos, Rio de Janeiro, v. 32, n.32, p. 185-208, 1997.

CASSAMA, Daniel Júlio Lopes Soares. Amílcar Cabral e a independência da Guiné-Bissau e Cabo Verde. 2014. Dissertação (Mestrado em Ciências Sociais) - . UNESP, Faculdade de Ciências e Letras., Araraquara, 2014.

CASTELO, Claudia. Novos Brasis" em África: desenvolvimento e colonialismo português tardio. Varia história., v.30, n.53,p. 507-532, 2014

CASTELO, Claudia. Passagens para África: o povoamento de Angola e Moçambique com Naturais da Metrópole. Porto: Edições Afrontamento, 2007.

CASTRO, Isabel Henriques. Território e identidade: O desmantelamento da terra africana e a construção da Angola colonial (c. 1872 - c. 1926). Lisboa, 2003. Sumário pormenorizado da lição de síntese apresentada a provas para obtenção do título de Professor Agregado do $4^{\circ}$ Grupo (História) da Faculdade de Letras da Universidade de Lisboa.

CRUZ, Elizabeth Ceita Vera. O Estatuto do indigenato e a legalização da discriminação na colonização portuguesa: o caso de Angola. Lisboa: Novo Imbondeiro. 2005.

FRANCO, Paulo Fernando Campbell. Amilcar Cabral: a palavra falada e a palavra vivida. 2009. Dissertação (Mestrado em História Social) - Universidade de São Paulo, São Paulo, 2009

FENTRESS, James; WICKMAN, Chris. Memória social. Lisboa: Portugal: Teorema. 1994.

HALBWACHS, Maurice. A memória coletiva. São Paulo: Centauro, 2004. 
HAMPATÉ BÂ, A. A tradição viva. In: KI-ZERBO (Coord.). História geral da África I:Metodologia e pré-história da África. São Paulo: Ática; Paris: UNESCO, 2012, p.181-218.

LE GOFF, Jacques. Memória. In: LE GOFF, Jacques. História e memória. 5. ed. Campinas: Editora da UNICAMP, 2003.

MATEUS, Dalila Cabrita e MATEUS, Álvaro. Angola 61 - Guerra Colonial e consequências. Alfragide: Texto Editores, 2011.

MEDINA, Maria do Carmo. Angola: processos políticos da luta pela independência. ed. Coimbra: Almedina, 2005.

MENDES, Afonso. A Huíla e Moçâmedes: considerações sobre o trabalho indígena. Lisboa : Junta de Investigações do Ultramar, 1958.

MENEZES, Solival. Mamma Angola: sociedade e economia de um país nascente. Prefácio de Paul Singer. São Paulo: Edusp; FAPESP, 2000, p. 139.

NASCIMENTO, Washington Santos. Minha mãe me entregou nas mãos do professor para fazer de mim o que quisesse e pudesse?: memórias da educação escolar em Angola.

Revista HISTEDBR On-line, v. 55, p. 231-249, 2014.

NASCIMENTO, Washington Santos. Gentes do Mato: os "novos assimilados" em Luanda. 2013. Tese (Doutorado em História Social) - Universidade de São Paulo, Faculdade de Filosofia Letras e Ciências Humanas, São Paulo, 2013

OLEG, Ignatiev. Amílcar Cabral. Moscovo: Edições Progresso.1984.

OLIVEIRA, Mario Antonio Fernandes. Reler África. Instituto de Antropologia. Universidade de Coimbra, 1990

PAREDES, Margarida Paredes. Deolinda Rodrigues, da Família Metodista à Família MPLA, o Papel da Cultura na Política. Cadernos de Estudos Africanos [Online], n.20, 2010, Disponível em: <http://cea.revues.org/135 ; DOI : 10.4000/cea.135>Consultado o 11 Junho 2016

PINTO, Wilmer Delgado Pinto. Caraterização do comando e liderança de Amílcar Cabral. Relatório científico final do trabalho de investigação aplicada. Lisboa: Academia Militar, 2014.

RICOEUR, Paul. A memória, a história, o esquecimento. Campinas/SP: Editora da Unicamp, 2007.

RODRIGUES, Alberto Leite. A indústria química nas colónias: elementos colhidos no cruzeiro de férias (1935). Revista de Chimica Pura Apllicada, Ano 11, n.II, p.67-77, 1936. 
Disponível em: http://www.spq.pt/magazines/RCPA/487/article/10001262/pdf. Acesso em 10 de Junho de 2016.

SANTOS, Daniel dos. Sociedade política e formação social angolana (1975-1985) Estudos Afro-Asiáticos. Rio de Janeiro: Editora Universidade Cândido Mendes, nº 32, Dez. 1997.

SANTOS, Maria Emilia Madeira dos. Nos caminhos de África: serventia e posse. ICTLisboa: Século XIX, 1998.

SEBASTIÃO, Adriano. Mérito do processo 50 foi a consciencialização do povo angolano. Agência Angola Press. Disponível em <http://www.angop.ao/angola/pt_pt/noticias/politica/2006/1/7/Merito-processo-foiconsciencializacao-povo-angolano,c361f1ae-fb29-4dco-a27f-cfba1ad66261.html>. Acesso em 02 de Fevereiro de 2016.

SEBASTIÃO, Adriano. Dos campos de algodão aos dias de hoje. Edição do Autor, 1993

SILVA, Elisete Marques. Impactos da ocupação colonial nas sociedades rurais do Sul de Angola, Lisboa: Centro de Estudos Africanos/ISCTE-Instituto Universitário de Lisboa, 2003. XITU, Uanhenga. “Mestre” Tamoda \& Kahitu: contos. São Paulo: Ática, 1984. 